\title{
Temporary stent as a bail-out device during percutaneous transluminal coronary angioplasty: preliminary clinical experience
}

\author{
J S R Gibbs, U Sigwart, N P Buller
}

\begin{abstract}
Objective-To evaluate the safety and efficacy of a prototype temporary stent (RX Flow Support Catheter, Advanced Cardiovascular Systems) in maintaining coronary perfusion and improving vessel patency in the event of acutely compromised flow complicating percutaneous transluminal coronary angioplasty.

Design-Prospective clinical study as part of a multicentre trial.
\end{abstract}

Setting-Regional cardiac centre catheterisation laboratory.

Patients-Eight patients undergoing routine percutaneous transluminal balloon coronary angioplasty in whom coronary artery dissection resulted in impaired coronary artery flow with angina or electrocardiographic ST segment shift, needing bail-out treatment at the time of the procedure.

Results-The RX Flow Support Catheter was successfully used and improved coronary flow in all cases, with a reduction in luminal stenosis and resolution of symptoms. The temporary stent was expanded for an average of 85 (range 30-209) minutes. In six patients it was used as a bridge to further treatment (permanent stent in four and coronary artery surgery in two) and two patients did not need further treatment.

Conclusion-The temporary stent was safe and effective in the acute management of coronary dissection. The main advantages are its ease and speed of use, and successful restoration of coronary flow both to the distal artery and to affected side branches pending definitive treatment.

(Br Heart $\mathcal{F} 1$ 1994;71:372-377)

Invasive Cardiology, Royal Brompton National Heart and Lung Hospital, London I S R Gibbs U Sigwart N P Buller Correspondence to: Dr N P Buller, Department of Cardiology, Royal Brompton National Heart and Lung Hospital, Sydney Street, London SW3 6NP. Accepted for publication 12 October 1993 tion with either an angioplasty balloon or an autoperfusion balloon to stabilise the dissection and thus limit ischaemia, ${ }^{78}$ permanent stents to hold the vessel open, ${ }^{9-11}$ laser bal-
Coronary artery dissection at the site of balloon angioplasty results in abrupt vessel closure in between $3 \%$ and $8 \%$ of coronary angioplasties. ${ }^{1-3}$ Various bail-out strategies have been devised to manage these loon angioplasty to tack up the dissection flap, ${ }^{12}$ and directional atherectomy to excise the dissection flap. ${ }^{13}$

These strategies have reduced the need for emergency coronary artery surgery in the management of abrupt closure. The results of emergency coronary artery surgery are compromised by the presence of acute myocardial ischaemia on arrival in the operating theatre. ${ }^{14}{ }^{15}$ This problem has been partially improved by autoperfusion catheters ${ }^{16}$ and the use of permanent stents for bailout. ${ }^{17}$

There remains a need for a bail-out device that ensures high coronary blood flow both to the distal artery and affected side branches and that is simple to use for operators with limited or no experience with permanent stents. As part of an international multicentre study, we have investigated a prototype temporary stenting device, (RX Flow Support Catheter, Advanced Cardiovascular Systems, USA). We evaluated the safety and effectiveness of this temporary stent in maintaining coronary perfusion and improving vessel patency when flow is compromised after coronary angioplasty.

\section{Patients and methods}

RX FLOW SUPPORT CATHETER

This consists of a temporary stenting catheter that provides an internal scaffold to the artery wall (fig 1). The catheter is used over an angioplasty guidewire 0.014 inches in diameter by a rapid exchange technique. The tip of the catheter is composed of a radio-opaque braided wire mesh cage ( $30 \mathrm{~mm}$ long) and is permanently attached to a 3.7 French catheter. There is a radio-opaque marker at each end of the cage.

A screw action manipulator on the proximal end of the catheter is used to expand the cage to the desired size and collapse it as required. As the cage expands it shortens. The cage can be expanded to any size up to a maximum diameter of $4 \mathrm{~mm}$ and exerts a low radial force (maximum $300 \mathrm{~mm} \mathrm{Hg}$ ) on the vessel wall. Because blood flows through the mesh cage, side branches that have been covered by the cage remain perfused. A side port is provided to maintain slow continuous flushing with heparinsed saline during expansion of the cage. During the procedure the 

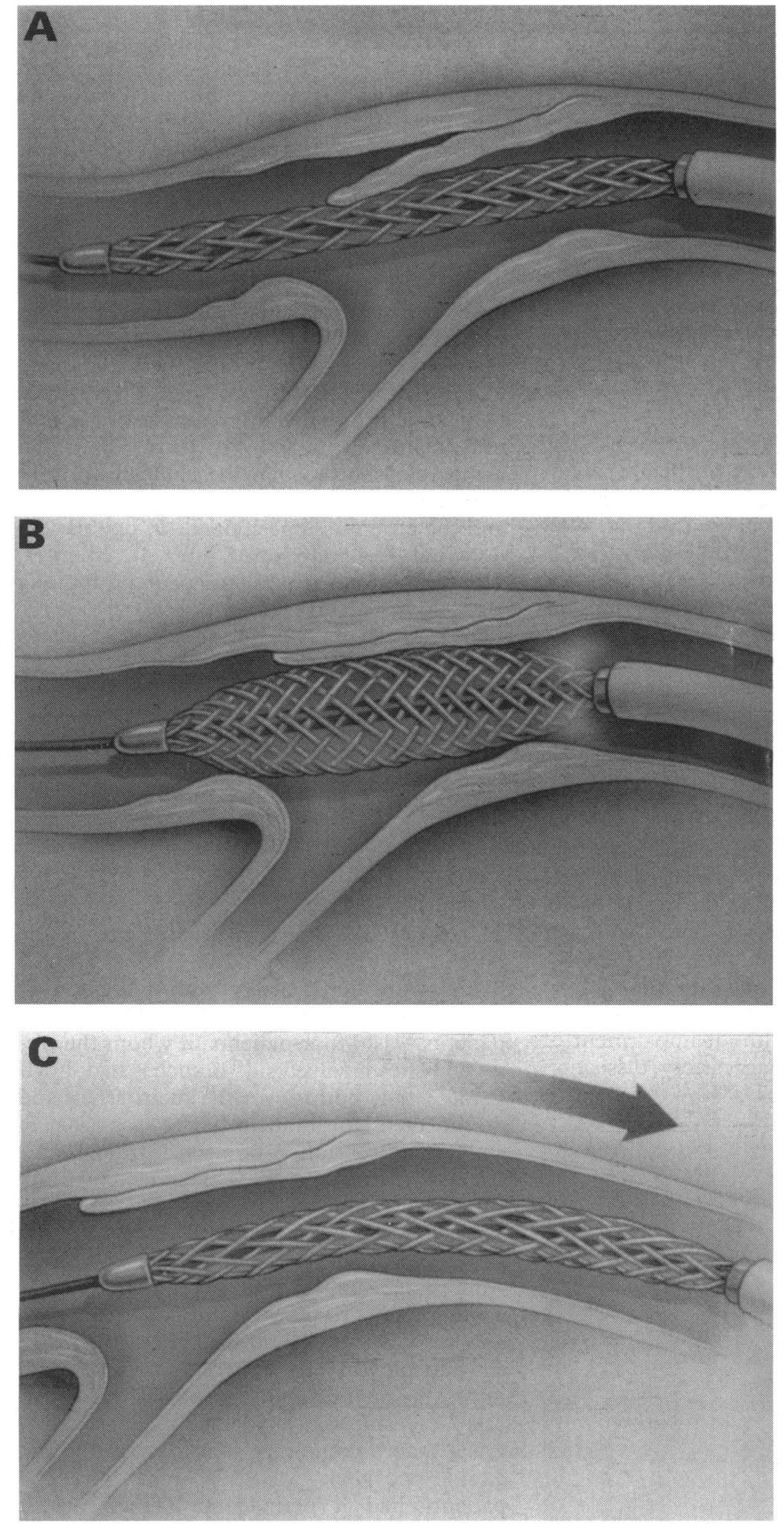

Figure 1 Schematic diagrams of the RX Flow Support Catheter (temporary stent). (A) Collapsed cage at the tip of the temporary stent is seen straddling a coronary artery dissection at the site of side branch. (B) Cage has been expanded, tacking the dissection flap back in place. Wire mesh cage causes minor obstruction to blood flow. (C) Cage is seen collapsed and is being withdrawn from coronary artery on the guidewire. Dissection flap remains tacked against the arterial wall.

\section{PATIENTS}

Eight patients (mean age 58.7 (range 41-69) years; six men) underwent the insertion of the RX Flow Support Catheter. Four patients had single vessel disease and four had multivessel disease. They were selected from those patients undergoing routine coronary angioplasty in whom there was acute impairment of coronary flow to TIMI Thrombolysis in Myocardial Infarction grade 2 or less after balloon inflation or a poor angiographic result needing intervention to prevent a flowimpeding condition and in whom symptoms or electrocardiographic changes were present. Four patients had chronic stable angina and four had unstable angina. All patients were pretreated with aspirin, and received 15000 IU heparin and $500 \mathrm{ml} \mathrm{10 \%} \mathrm{dextran} \mathrm{at} \mathrm{the}$ time of angioplasty. Patients were candidates for coronary artery surgery. Patients were excluded if they were undergoing angioplasty to the left main stem or an ostial stenosis or if the vessel was larger than the maximum size of the cage.

Patients gave informed consent to the use of the temporary stent which was approved by the ethics committee of the Royal Brompton National Heart and Lung Hospital.

STUDY PROTOCOL

Before the temporary stent was used, the angioplasty balloon was withdrawn leaving the angioplasty guidewire across the lesion. The temporary stent was then introduced over the angioplasty guidewire. The cage was positioned across the stenosis and then expanded to the diameter of the artery. A control angiogram confirmed the positioning of the cage: the cage was collapsed and reexpanded at a different site if the first position was not optimal.

During the study blood pressure and the electrocardiogram were continuously monitored. Anticoagulation was monitored by measuring the activated clotting time immediately before insertion of the stent and at $\mathbf{3 0}$ minute intervals thereafter. Fluoroscopy, and when necessary angiography, was used to monitor the position of the stent every five minutes.

After an initial expansion for 30 minutes the wire cage was collapsed and withdrawn into the guide catheter and the state of the vessel was reassessed by angiography. The operator then decided whether to re-expand the cage for longer or abandon the procedure. After the second period of expansion, which lasted up to 30 minutes, the cage was again withdrawn into the guide catheter and the angiography repeated. If the result was satisfactory no further treatment was undertaken. If the result was unsatisfactory then the operator decided either to insert a permanent stent or send the patient for coronary artery surgery. In those patients sent for surgery the cage was re-expanded to maintain coronary flow until after cardiopulmonary bypass had been established in the operating theatre.

Creatine kinase (CK) and its MB fraction cage can be expanded and collapsed as required to alter its position. At the end of the procedure the cage is collapsed and the catheter withdrawn leaving the guidewire in place as appropriate. 
Individual patients who underwent the insertion of a flow support catheter (FSC)

\begin{tabular}{lllcl}
\hline Vessel & Diameter (mm) & $\begin{array}{l}\text { Flow before FSC } \\
\text { (TIMI grade) }\end{array}$ & $\begin{array}{c}\text { Duration of FSC } \\
\text { expansion (min) }\end{array}$ & Outcome \\
\hline LAD & $2 \cdot 75$ & 0 & 50 & No more treatment \\
RCA & 3 & 2 & 33 & Stent \\
LAD & $2 \cdot 5$ & 0 & 209 & Coronary artery \\
& & 2 & 30 & surgery \\
LAD & 3 & 2 & 60 & Stent \\
LAD & 3 & 3 & 60 & Double stent \\
LAD & 3 & 2 & 60 & Stent \\
LAD & $2 \cdot 5$ & 1 & 180 & No more treatment \\
LAD & 3 & & & Coronary artery \\
& & & surgery \\
\hline
\end{tabular}

FSC, RX Flow Support Catheter; LAD, left anterior descending coronary artery; RCA, right coronary artery; Stent, permanent stenting with a Palmaz-Schatz Stent Johnson and Johnson, USA); Double stent, indicates the use of tandem permanent stents.

were measured in blood drawn before angioplasty, eight hours and 24 hours after the operation and before discharge from hospital. Twelve lead electrocardiograms were recorded at the same times.

All patients were reviewed three months after the procedure. If patients had not undergone further treatment after the use of the RX Flow Support Catheter they underwent repeat coronary angiography.

\section{Results}

Seven patients had dissections in the proximal or mid-left anterior descending coronary artery and one patient in the mid-right coronary artery. The table shows the details of the vessels treated. Four patients had a coronary artery dissection partially impeding anterograde coronary artery blood flow, three patients had a dissection causing abrupt closure, and one patient without impairment of flow had a large coronary artery dissection

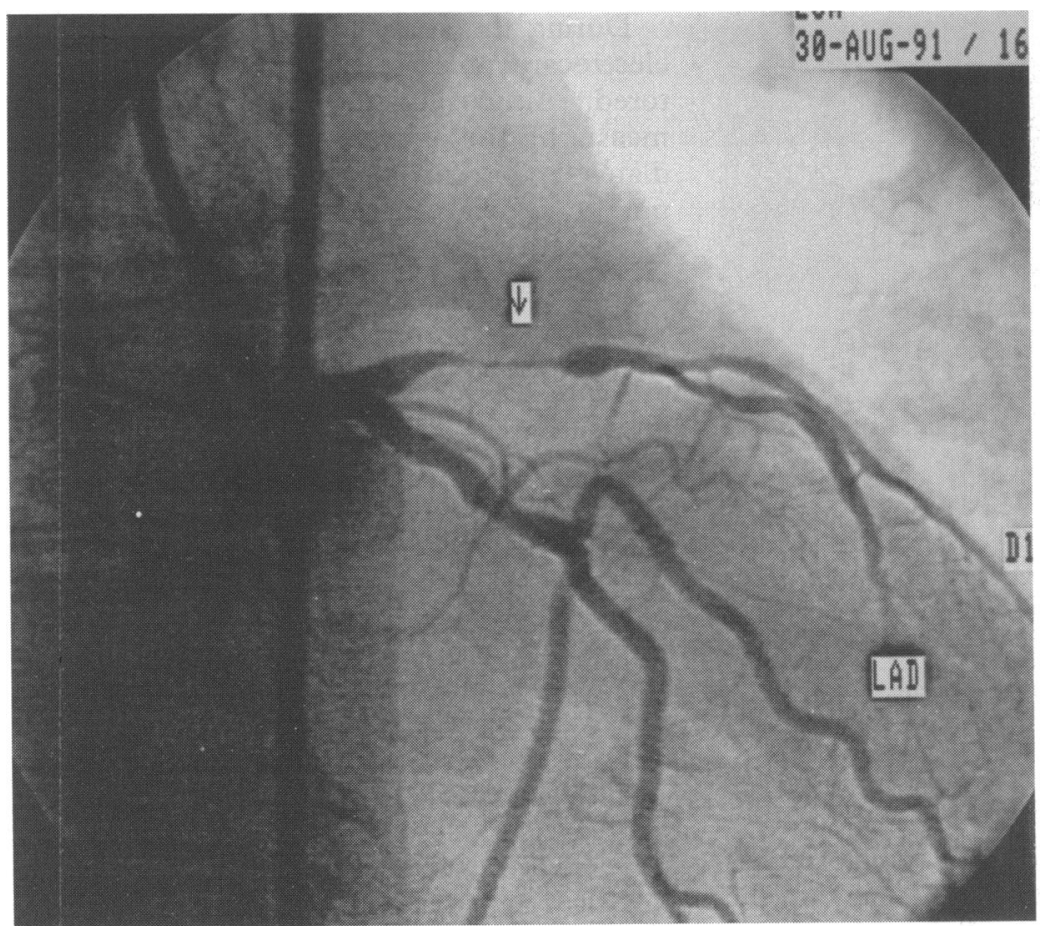

Figure 2 One of a series of angiograms of one patient. Showing left coronary artery injection in anterior posterior projection. Severe proximal stenosis of left anterior descending coronary artery (LAD) at the origin of first diagonal (D1) is indicated by arrow. that was considered likely to cause occlusion. In seven of eight cases the dissection involved a side branch of the artery. Six patients had angina associated with the impaired perfusion and four patients had ST segment changes on their electrocardiogram. The RX Flow Support Catheter was used for an average (range) of 85 (30-209) min.

\section{USE OF CATHETER}

The RX Flow Support Catheter was prepared and used in all patients in less than six minutes. Preparation of the catheter took less than three minutes. The cage was expanded to the natural diameter of the artery in four patients and to $0.5 \mathrm{~mm}$ greater than the natural diameter in four patients. The first angiogram showed that the catheter was not optimally positioned in seven of eight patients and the cage was repositioned. In one patient impaired flow developed after 10 minutes. This was corrected by minor repositioning without any adverse consequences.

\section{SAFETY}

During the studies the patients remained haemodynamically stable once coronary perfusion had been restored. Anticoagulation as measured by the activated clotting time was maintained in the range $300-750 \mathrm{~s}$, additional boluses of $5000 \mathrm{IU}$ heparin were given as required.

\section{IMMEDIATE RESULTS}

The result of expansion of the cage of the flow support catheter produced TIMI grade 3 flow to the distal artery with reduction in luminal stenosis to less than $10 \%$ in all patients. Also, four patients in whom the dissection sites involved side branches had TIMI grade 3 flow both down the main artery and the affected side branch. There was relief of angina and resolution of electrocardiographic changes in all patients while the temporary catheter was in place.

EARLY OUTCOME

After expansion of the cage a satisfactory angiographic result was obtained in two patients who needed no further treatment. In six patients (in one of whom there was an improvement in luminal stenosis) the angiographic result was inadequate: mean TIMI grade before temporary stenting was 1.7 and after removal it was $2 \cdot 3$. Four of these patients had a permanent Palmaz Schatz stent (Johnson and Johnson, USA) inserted, all with a satisfactory result. Figures 2 to 6 show the angiographic sequence of one of these patients.

Two particularly long expansion times of 180 and 209 minutes were needed when the temporary stent was used as a bridge to coronary surgery after dissection of the left anterior descending coronary artery. One of these arteries was considered to be too narrow for insertion of a permanent stent and the length of the dissection precluded permanent stenting in the other. In both cases vessel patency could not be maintained without 


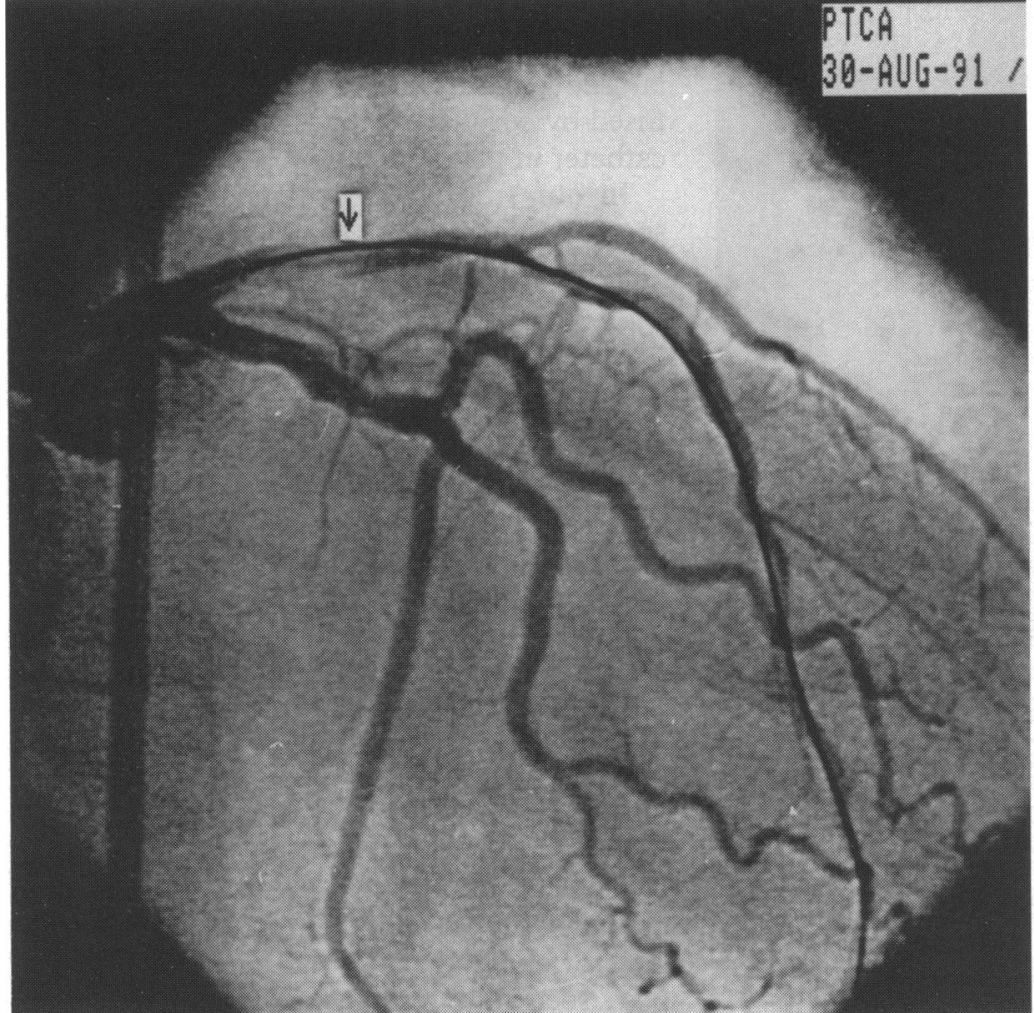

Figure 3 One of a series of angiograms in one patient, showing that after balloon angioplasty there was a large local dissection of the left anterior descending at angioplasty site indicated by arrow. Guidewire is seen in the left anterior descending coronary artery.

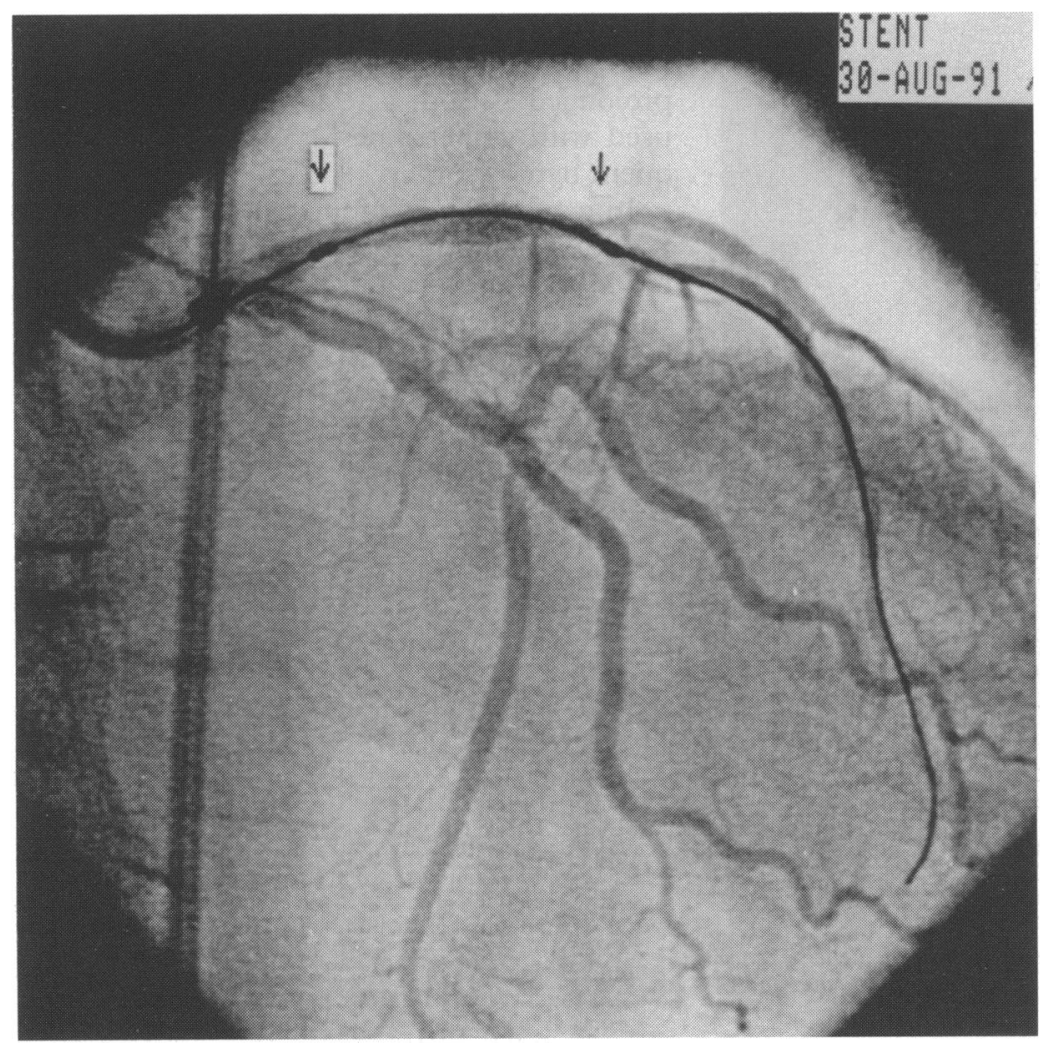

Figure 4 One of a series of angiograms in one patient, showing $R X$ Flow Support

Catheter with its cage expanded across the dissection. There has been an improvement in the luminal stenosis with TIMI grade 3 flow to the distal coronary artery. Arrows indicate markers at either end of expanded cage.

the temporary stent. As the catheter maintained good coronary perfusion the patients were not rushed to the operating theatre immediately but underwent surgery when a theatre became available. These two patients arrived in the operating theatre without chest pain or electrocardiographic changes. Flow support was maintained until cardiopulmonary bypass had been established and the surgeon was ready to graft the affected coronary artery. Both patients received internal mammary grafts and one patient also received a vein graft to the first diagonal branch, which was affected by the coronary dissection and in which flow had been maintained by the flow support catheter.

On withdrawal of the catheter, a piece of debris about $1 \mathrm{~mm}$ in diameter was found in the cage in two patients. Histology of one of these cases showed that the debris was fibrin. No patient sustained a myocardial infarction as indicated by electrocardiographic changes or a rise in the $\mathrm{CK}$ or CK-MB fraction during their stay in hospital.

\section{LATE OUTCOME}

Follow up at three months showed that six of eight patients remained symptom free with no objective evidence of active myocardial ischaemia on the resting and exercise (no data in two patients) electrocardiograms. Of the two patients with recurrent angina, one underwent angioplasty to a different vessel one month after flow support; and one patient who had a definitive result with the flow support catheter alone underwent repeat angiography that showed a $99 \%$ restenosis with TIMI grade 1 flow. The second patient with a definitive result from the flow support catheter refused repeat angiography because he felt well. The patients who underwent coronary surgery had normal left ventricular function with no regional wall motion abnormalities as assessed by echocardiography and gated blood pool scanning.

\section{Discussion}

Coronary artery occlusion after percutaneous transluminal coronary angioplasty is a serious complication. It is associated with a high incidence of myocardial infarction and increased mortality compared with uncomplicated coronary angioplasty. ${ }^{5}$ As abrupt vessel closure after coronary angioplasty is unpredictable, effective bail-out devices are necessary to minimise myocardial ischaemia.

Despite a wide range of methods and devices to overcome this problem in the catheter laboratory, about one third of patients in this situation require emergency coronary artery surgery. ${ }^{45}$ The results of this are less good than elective surgery, and have an incidence of $Q$ wave myocardial infarction varying from $25 \%$ to $57 \%$ and mortality from $1.4 \%$ to $19 \% .{ }^{14}{ }^{15}$ The poor results seem to be associated with preoperative ischaemia that also mitigates against the use of internal mammary artery grafts. ${ }^{14}$ Attempts to reduce ischaemia with an autoperfusion catheter have shown a reduction in perioperative myocardial infarction and an increased use of internal mammary artery grafts. ${ }^{16}$ Strategies to stabilise or reverse myocardial ischaemia may improve long-term outcome. 


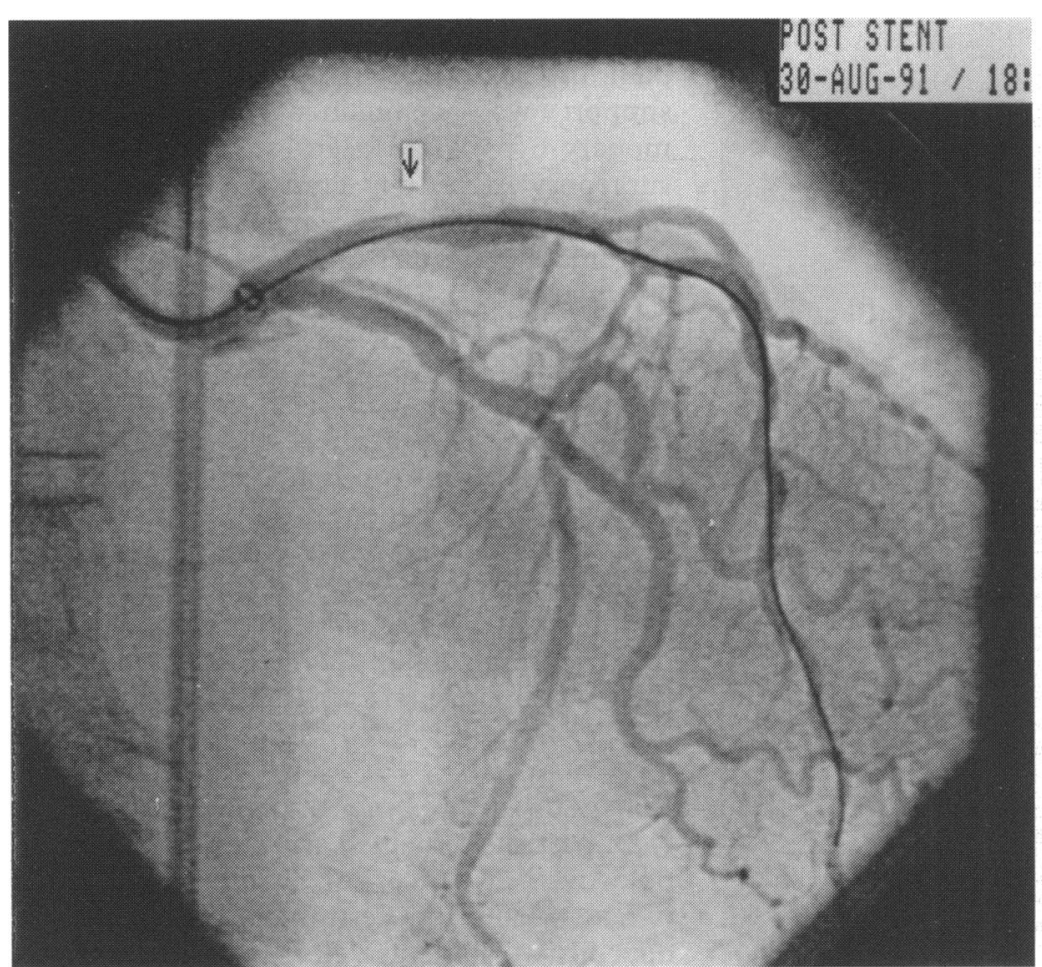

Figure 5 One of a series of angiograms in one patient, showing improvement in vessel appearance after 60 min of cage expansion, none the less the result remains unsatisfactory.

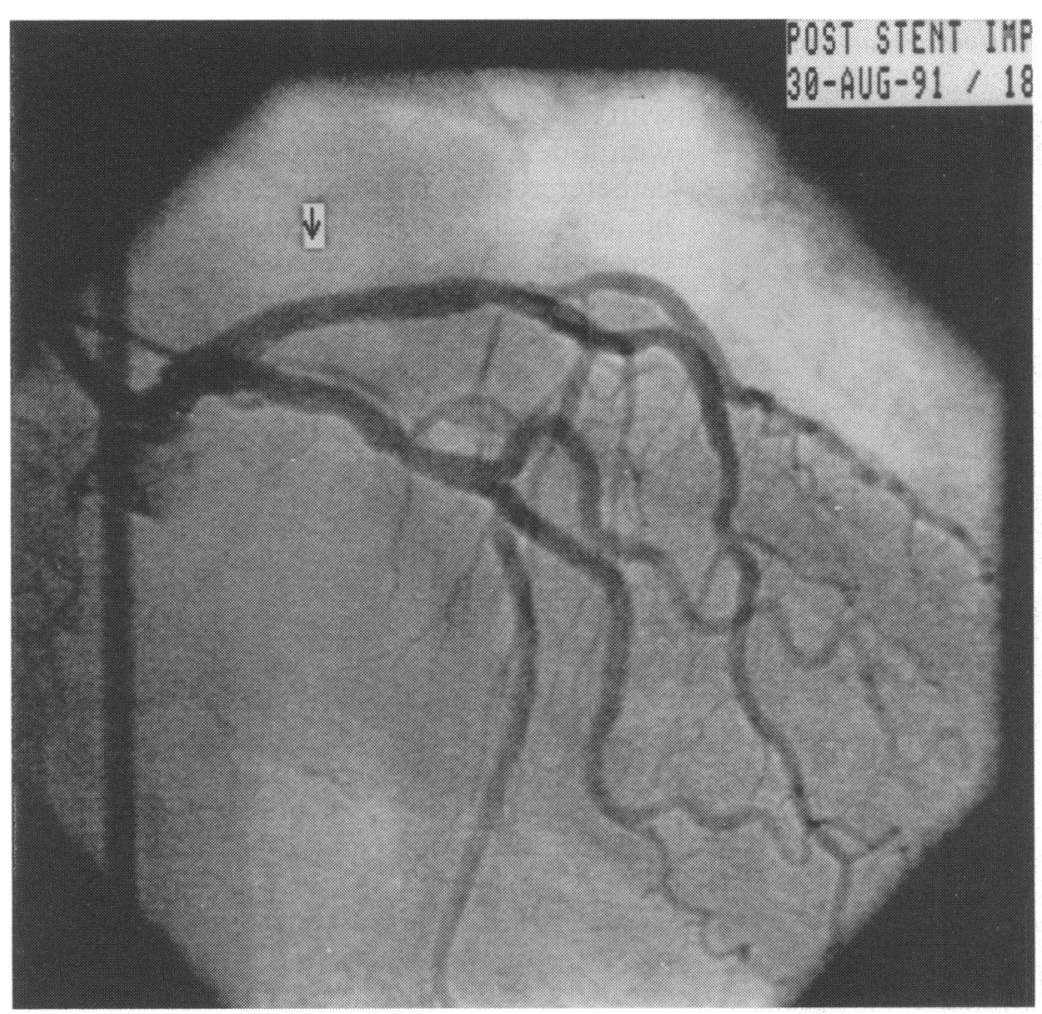

Figure 6 One of a series of angiograms in one patient, showing a permanent stent (Palmaz Schatz, fohnson and fohnson, USA) inserted at the angioplasty site (indicated by arrow). port catheters regional myocardial blood flow was not significantly different in left ventricular subepicardium and subendocardium perfused by coronary arteries with or without the catheter in place. ${ }^{18}$

In our study, this catheter seems to have specific advantages as a bale-out device. Compared with autoperfusion balloons, the ability to alter cage size means that one catheter size will fit any artery. The wire mesh cage is less obstructive than a balloon and there is TIMI grade 3 distal flow. Unlike perfusion balloons, side branches are also perfused. Both the lower flow and occlusion of side branches may be reasons why perfusion balloons do not completely salvage the ischaemic myocardium. ${ }^{19}$

Unlike permanent stents, which are not clearly better than conventional treatment in the management of abrupt vessel closure, ${ }^{20}$ the flow support catheter is suitable for vessels less than $3 \mathrm{~mm}$ diameter. The RX Flow Support Catheter is easily seen on fluoroscopy and can be repositioned if required. When the flow support catheter is used in place of a permanent stent it avoids the problems of anticoagulation and subacute thrombosis seen with permanent stents. ${ }^{101721}$

In our preliminary experience, the $\mathrm{RX}$ Flow Support Catheter was effective at reversing ischaemia but less successful at providing definitive treatment during a one hour expansion. An unexplored use of this device might be to provide coronary perfusion for a prolonged period, a technique that has been used with catheter perfusion to avoid subsequent bypass surgery. ${ }^{22}$

In conclusion, we found that the prototype RX Flow Support Catheter was safe and simple to use after an unsatisfactory result from coronary balloon angioplasty. It was successful as a bail-out device in all eight patients. It restored normal coronary flow both to the distal artery and to side branches, reduced luminal stenosis, and resolved angina and electrocardiographic changes. Its effectiveness as a bail-out device may add a new dimension of security to coronary angioplasty.

1 Ellis SG, Roubin GS, King SB, et al. In-hospital cardiac mortality after acute closure after coronary angioplasty: analysis of risk factors from 8,207 procedures. $\mathscr{f} \mathrm{Am} \mathrm{Coll}$ Cardiol 1988;11:211-6.

2 Holmes DR, Holubkov R, Vliestra RE, et al. Comparison of complications during percutaneous transluminal coronary angioplasty from 1977 to 1981 and from 1985 to 1986: The National Heart, Lung, and Blood Institute Percutaneous Transluminal Coronary Angioplasty Registry. $₹ \mathrm{Am}$ Coll Cardiol 1988;12:1149-55.

3 Lincoff AM, Popma J, Ellis SG, Hacker JA, Topol EJ. Abrupt vessel closure complicating coronary angioplasty: clinical, angiographic and therapeutic profile. plasty: clinical, angiographic and

4 Sinclair IN, McCabe CH, Sipperley ME, Baim DS. Predictors, therapeutic options and long-term outcome Predictors, therapeutic options and long-term outcom

We have used the prototype flow support catheter to restore and maintain TIMI grade 3 coronary blood flow in eight patients with either acute impairment of coronary flow or a poor angiographic result with threatened vessel closure after percutaneous transluminal coronary angioplasty.

In animal studies with prototype flow supand consequences of periprocedural occlusion. The 1985-1986 National Heart, Lung and Blood Institute
Percutaneous Transluminal Coronary Angioplasty Percutaneous Transluminal Coro

6 de Feyter PJ, van den Brand M, Jaarman GJ, van Feyter PJ, van den Brand M, Jaarman GJ, van
Domberg R, Serruys PW, Suryapranata H. Acute coronary occlusion during and after percutaneous transluminal coronary angioplasty. Frequency, prediction, clinical course, management and follow-up. Circulation 1991;83: 927-36. 
7 Quigley PJ, Hihohara T, Phillips HR, et al. Myocardial protection during coronary angioplasty with an autoperfusion balloon catheter in humans. Circulation 1988,

8 Ieits.156-63.

Leitschuh ML, Mills RM, Jacobs AK, Ruocco NA Jr, LaRosa D, Faxon DP. Outcome after major dissection during coronary angioplasty using the perfusion balloon catheter. $A m \mathcal{F}$ Cardiol 1991;67:1056-60.

9 Sigwart U, Urban P, Golf S, et al. Emergency stenting for acute occlusion after coronary balloon angioplasty. Circulation 1988;78:1121-7.

10 de Feyter $P$, DeScheerder I, van den Brand M, Laarman GJ, Suryapranata H, Serruys PW. Emergency stenting for refractory acute coronary artery occlusion durin coronary angioplasty. Am 7 Cardiol 1990;66:1147-50.

11 Roubin GS, Cannon AD, Agrawal SK, et al. Intracoronary stenting for acute and threatened closure complicating percutaneous transluminal coronary angioplasty. Circulation 1992;85:916-27.

12 Jenkins RD, Spears JR. Laser balloon angioplasty. A new approach to abrupt coronary occlusion and chronic restenosis. Circulation 1990;81 (suppl IV):IV-101-8.

13 Lee TC, Hartzler GO, Rutherford BD, McConahay DR Removal of an occlusive coronary dissection flap by using an atherectomy catheter. Cathet Cardiovasc Diagn using an atherecto

14 Talley JD, Weintraub WS, Roubin GS, et al. Failed elective percutaneous transluminal coronary angioplasty requiring coronary artery bypass surgery. In-hospital and late clinical outcome at 5 years. Circulation 1990;82

15 Buffet P, Danchin N, Villemot JP, et al. Early and longterm outcome after emergency coronary artery bypass surgery after failed coronary angioplasty. Circulation 1991;84(suppl III):III-254-9.

16 Sundram $P$, Harvey JR, Jun on RG, Schwartz MJ, Baim DS. Benefit of the perfusion catheter for emergency coronary artery grafting after failed percutaneous transluminal coronary angioplasty. Am f Cardiol 1989;63: 282-5.

17 Haude M, Erbel R, Straub U, Dietz U, Schatz R, Meyer $J$. Results of intracoronary stents for management of coronary dissection after balloon angioplasty. $A m \mathcal{F}$ Cardiol 1991;67:691-6.

18 Clugston $R$, Oesterle SN, Matthews R, Dawson R, Garrison M, Alker K, et al. Flow support catheter for prolonged maintenance of coronary blood flow. Cathet Cardiovasc Diagn 1991;24:308-14.

19 Turi ZG, Rezkalla S, Campbell CA, Kloner RA. Amelioration of ischemia during angioplasty of the left anterior descending coronary artery with an autoperfusion catheter. Am F Cardiol 1988;62:513-7.

20 Lincoff AM, Topol EJ, Chapekis AT, George BS, Candela RJ, Muller DWM, et al. Intracoronary stenting compared with conventional therapy for abrupt vessel closure complicating coronary angioplasty: a matched case-control study. F Am Coll Cardiol 1993;21:866-75.

21 Sigwart U, Puel J, Mirkovitch V, Joffe F, Kappenberger L Intravascular stents to prevent occlusion and restenosis after transluminal angioplasty. $N$ Engl f Med 1987;316: after tran.

22 Ciampricotti R, Dekkers PJWM, El Gamal MIH, Van Der Krieken AM, Relik THFM. Catheter reperfusion for failed emergency coronary angioplasty without subsequent bypass surgery. Cathet Cardiovasc Diagn 1989;18:159-64. 